\title{
DETERMINANTS OF ADULT MOTIVATION TO ENROLL \\ IN NON-CREDIT PROGRAMMES AT CEES IN \\ THE COLLEGE OF THE BAHAMAS: \\ A FACTOR ANALYTIC APPROACH
}

\author{
Nsima D. Udoko \\ Natural Sciences Division, The College of The Bahamas
}

There is a plethora of studies on why adults participate in educational activities, but there is a need for additional information from both unique respondent groups of participants and from a culture with restricted educational facilities. This study reports the results of a group of adult learners facing limited educational offerings, who enrolled in non-credit programmes at Continuing Education and Extension Services (CEES) of The College of The Bahamas. The hypothesis that reasons for adult participation in non-credit programmes would factor into at least eight groups was tested using 134 adult learners enrolled in various non-credit programmes at CEES. Eight groups of reasons were identified using the PFA approach. The results were further interpreted in light of the traditional motivational framework and a model was developed to explain the adult participation motivational orientations in an educational activity.

\section{INTRODUCTION}

Like many dynamic institutions, the labour market in developing and developed countries alike, has experienced rapid changes over the past decade. These changes are clear indicators of the present focus and expectations of the socio-economic and industrial institutions engaging the labour force and also evidence of the ever changing structure of the labour force.

The mind intriguing advances in technology in recent times make the situation even more complex. Wagner (1994) pointed out that as instructional technologies become more powerful, pervasive, affordable and user friendly, and adaptable, educators become more hopeful that these technologies would help to bring about dramatic improvements in educational practice. Therefore, instructional design is now viewed as a systematic approach to performance problem solving and also as a systematic method of tailoring theoretical prescriptions for instruction to fit specific application contexts.

The challenges arising from rapidly changing labour market demands have become a global concern requiring that the roles of the basic stages of education be redefined to equip people for the continuous process of skill adjustment. Therefore, the quality of education is now measured by its ability to prepare the labour force for the needs and challenges of the market. In the January 1996 Meeting of Education Ministers of OECD 
countries concerns high on the meeting's agenda included "improving the transition pathways between education and workforce..., the transition from school to work and

higher education; and roles and responsibilities of all partners - including governments and the learners themselves - in implementing and financing opportunities for life long learning" (OECD,1996). In Poland, like many other countries, retraining is considered a major goal in the active Labour Programmes (World Bank, 1996).

With the global structural adjustment of the educational system, redefinition of goals of education and training coupled with workshops, conferences, in-house training, seminars, short courses and particularly recent advancement of the delivery system technology (Miller, 1992; Moore, 1990), the emergent labour force is able to keep pace with the rapidly changing labour market demands.

The College of The Bahamas, over the last decade has greeted this challenge with the seriousness and concern it deserves. The College through the establishment of a Continuing Education and Extension Services (CEES) Department has since expanded its services to the community to accommodate the demands of the labour market and the labour force, and also extended its services to the Family Islands. CEES in addition to offering credit courses also offer a variety of non-credit/non-certificated programmes to service a wide range of interests, ranging from hobby-oriented through career to skill-aquisition-oriented programmes in general and specialised interests such as Engineering, Catering, Fashion Design, Baking and Hospitality among others. Many adults from various communities have participated in these programmes. Some adults participate in order to acquire knowledge and skills for professional and personal development and others participate as means of pursuing personal interests. A number of factors motivate adults to enroll in a programme at CEES.

\section{REVIEW OF THE LITERATURE AND THEORETICAL FRAMEWORK}

There is a plethora of studies almost exclusively from developed nations on participation motivation of adult learners. These include pioneer studies by Houle (1961), Sheffield (1961), Boshier (1971, 1982), Nicholson (1955) and Douglah (1970) and recent studies by Christmas (1990), Birkenholz, Harbstreit and Law (1990), Miller (1992) and Thompson (1992). Houle's (1961) pioneer study triggered off many studies on why adults choose to learn or not to learn based on a concept of orientations towards learning. Boshier $(1971,1982,1983)$ further developed in Houle and Sheffield's Education. Participation Scale (EPS) from a three-motivational factor group to a six-factor scale with forty items, each based on a four point-scale. Miller (1992) tested Boshier six factor EPS and concluded that knowledge of the motivations of adult learners in a specific programme may provide valuable insight into the kinds of learners the programme attracts. He further suggested that programme planning should be tailored to specific requirements and/or the needs of participants. Boshier (1991), Burgess (1971), Christmas (1990) and Miller (1992) presented elaborate discussions and summary results on Participation Motivation Studies, therefore, we refer readers to these refer- 
ences for further details.

This study is an effort to complement previous studies using a unique respondent group of participants in non-credit programmes from a culture with limited educational facilities. This would, therefore, serve as a basis from which to compare similar respondents in future studies. The Participation Motivation Studies have been based on the motivational frame-work in the psychology of learning. The traditional principle of psychology maintains that people are endowed with tendencies which cause them to maintain equilibrium or a state of synchrony between their constituent parts. This equilibrium is disturbed by tension which makes the individual loose the state of equilibrium, which we may from now on refer to as the " normal state". To restore balance behaviours must be initiated to ward off those disruptive forces which cause tension or threat. Failing to do this, may result in worsening the state of dis-equilibrium thereby increasing tension until the body system breaks down. Boshier (1982) maintained that behaviour aimed at restoration of balance may induce a state identical to that existing prior to increased tension, but in the case of adult education participation, it probably results in balance at new levels.

In this study we hypothesize that adult needs generate tension which mounts upwards until the need or needs are fulfilled. The learning process seems to be an avenue through which adults satisfy their needs to relieve tension and this learning may be formal or informal. On completion of a learning process experience is gained, tension is reduced and particular needs are met, and a new level of "normal state" is attained.

An adult education participation may be seen as a motivated behaviour (ACTION) in response to the desire to satisfy specific needs in order to attain a new level of synchrony in the body system. In light of the above thesis, an adult is motivated to participate in an educational programme in order to check disruptive forces (tension) and satisfy specific needs thereby attaining a higher level of synchrony among the constituent parts of the system. This concept of equilibrium state may best be illustrated with the following model:

Fig. 1: A Model of Equilibrium State of An Adult Learner

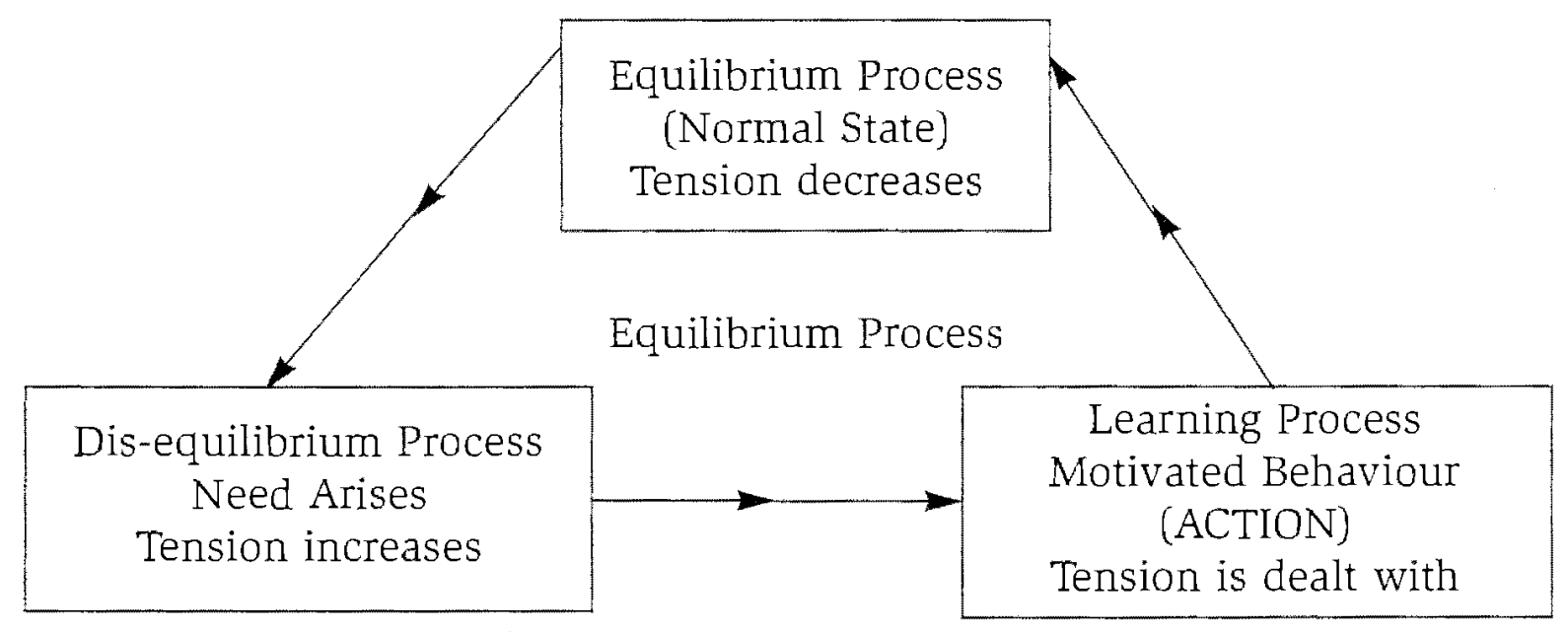


This model is a three-stage process. The time an adult learner spends at each stage varies from person to person. An adult remains in the "normal state" as long as no need(s) is (are) identified and tension is reduced. As soon as the adult identifies a need or group of needs, tension increases and the individual moves into a stage of disequilibrium and remains there until a defined line of ACTION (motivated behaviour) is initiated (that is the adult chooses to participate in a particular learning process). It is important to note that specific needs must be followed by a corresponding learning process if the intention is to satisfy these needs. In the learning process, experiences are acquired and materials learnt resulting in antidotes for reducing tension.. When learning is completed, tension is relieved and "normal state" returns. In this model, once the learning process is completed successfully, the adult learner never returns to the same level of the normal state prior to tension increase, but to a higher (new) level of normal state (needs are satisfied).

\section{PURPOSE AND OBJECTIVES}

It is certain that educational programmes offered by CEES have contributed immensely not only to personal development and recreational needs of the Bahamian citizenry, but also to the professional development of the work force. This study had a dual purpose:

1) to explicate the motivation orientations of the Bahamian adult learner by identifying and describing types of adults as defined by their percieved motivations to participate in CEES programmes;

2) to provide information on the needs of the Bahamian workforce which may serve as a rationale both for the development of CEES programme and expansion of its services to the wider public.

In order to achieve these broad objectives the following specific research objectives were defined:

a) to identify factors motivating adult learners who choose to participate in non-credit programmes at CEES;

b) to compare the differences in identified motivation orientations in terms of the respondents' characteristics. 


\section{THE HYPOTHESIS}

After reviewing the reasons why adult learners participate in educational activities in the literature, the investigator hypothesized that thirty-five (35) reasons motivated Bahamian adult participation in non-credit programmes at CEES and that these reasons would factor into at least eight groups presented in Table 1 below, although we maintain the possibilty of identifying other factors.

Table 1: Means and Standard Deviations of Motivation Indicators $(n=34)$

Participation Motivation Indicator

Mean SD

I. Intrinsic Socio-Personal Factor

1.97

1. To share common interest with my spouse or friend

2. To identify with congenial people

1.93

1.14

3. To fulfill a need for personal association or friendship

2.07

4. To participate in group activity

5. To make new friends

1.86

6. To improve my social relationship

7. To improve or maintain my social position

2.41

8. To be accepted by others

II. The Need to Escape Undesirable Conditions

10. To escape television

1.50

1.09

11. To overcome the frustration of day to day living

1.44

1.58

12. To escape an unhappy relationship

13. To have a break from the routine of home or work

1.59

15. To have a few hours away from responsibilities

1.35

16. To get a relief from boredom

17. To stop myself from becoming a "Cabbage"

III. The Need for Self-Actualisation

9. To gain insight into my personal problems

14. To provide a contrast to the rest of my life

18. To escape the intellectual narrowness of my occupation

IV. The Need for Professional Advancement

19. To provide a contrast to my previous education

20. To secure professional advancement

21. To acquire a higher professional status

22. To increase my professional competence

23. To keep up with my competition

V. The Need to Define a Career Path

24. To supplement a narrow previous education

25. To acquire knowledge that will help me with other 
27. To help me pursue a degree, diploma or certificate programme in my chosen area of study

\section{The Need to Serve the Community}

28. To become a more effective citizen of my country

29. To be well prepared to serve my community

$2.27 \quad 1.16$

30. To understand more about human nature

$2.21 \quad 1.21$

31. To improve my ability to fulfill a felt obligation

$2.57 \quad 1.24$ to community

32. To improve my ability to participate in community work

VII. The Need to Fulfill External Expectations

33. To carry out recommendations of some persons in authority

34. To fulfill expectations of others

VIII. The Need for Increased Monetary Returns

35. To obtain an increase in salary

$2.17 \quad 1.15$

$2.27 \quad 0.97$

$2.28 \quad 1.19$

$2.25 \quad 1.24$

$3.07 \quad 1.23$

$3.07 \quad 1.23$

\section{METHODOLOGY}

The methodolgy of the study is discussed in three subsections: Data-Collection, Instrument and Procedures for Analysis.

\section{Data-Collection}

A programme offered at CEES was considered non-credit if it did not directly or indirectly contribute to the credit requirements for the award of a Bachelor's degree, an Associate degree or a formal diploma or a certificate awarded by The College of The Bahamas or any recognised professional body.

The population for this study comprised all persons of eighteen years (18) and above enrolled in a non-credit programme at CEES, The College of The Bahamas. Because of communication difficulties, limited resources and time, Family Island participants were excluded. Therefore, participants surveyed were residents of New Providence enrolled in non-credit programmes at CEES on a part-time basis. The duration of a non-credit programme was between six to fourteen weeks.

During the Fall of 1996, 693 adults enrolled in at least one programme offered at CEES in New Providence, out of which 309 adults enrolled in credit related programmes and 384 enrolled in non-credit programmes. Data were collected from a randomly selected sample of 154 participants in non-credit programmes, yielding 135 usable responses. The final sample constituted 35 percent of the target population, hence was considered statistically a large sample. Respondents were asked to complete the surveys after being informed of the purpose, voluntary nature and confidentiality of their 
responses.

The percentage of non-responses was calculated to be 12.3 percent which was judged as reasonably small and insignificant, hence results are capable of valid inference. Participants were enrolled in the following types of programmes: College Entrance Review Programme (CERP), Mathematics for Secondary School Teachers, Secretarial Courses, Tutorial and Personal Development Courese.

\section{INSTRUMENT}

An instrument was designed to collect demographic and situational data from the respondents. This instrument was designed solely for the purpose of collecting data on the reasons why adults participate in non-credit programmes. Many people cannot express reasons for involvement in an educational activity. Yet still, others are not precise in stating their reasons, while others give mixed reasons which may not be related to the objectives and contents of the programme (Burgess, 1971).

To identify reasons why individuals engage in educational activity is an ardous task because of the complexity and diversity of the pattern of influential reasons; and in addition, some participants do not actually know the reasons why they engage in such activities. Therefore, the basic assumption underlying the development of the instrument was that adult learners participating in non-credit programmes have well-defined goals which can be measured with a considerable degree of accuracy. However, we admit some exceptions in which the participants do not have well-defined goals which can be measured with some degree of accuracy.

After the review of studies on factors determining motivational orientations of adult learners by Sheffield (1964), Miller (1992), the researcher developed a 35-item instrument which he called Reasons for Educational Activity Participation (REAP).

Permission was obtained from Professor Bruce Miller to include some of the items from his Education Participation Scale (EPS) in REAP (Miller, 1992), and REAP was based on a four point scale of responses with 1 representing "No Influence", 2 "Little Influence", 3 "Significant Influence", and 4 "Very Much Significant Influence". The researcher believed that items of REAP would factor into at least eight (8) groups which, are given in Table 1.

Two kinds of reliability were determined for the items of REAP - Cornblach's (1972) Alpha and item reliability coefficients with an average of 0.82 for the entire instrument. Nunnally (1976) suggests a reliability co-efficient of 0.50 to 0.60 as reasonably significant.

\section{Procedures for Analysis}

Descriptive statistics were used to describe the socio-demographic characteristics of the participants. In order to identify the factors contributing an individual's decision to enroll in non-credit programmes, the responses to the thirty-five (35) items of REAP 
were analysed by the Factor Analytic approach. This method is often used to isolate and identify the hidden factors that are common to a large number of inter-related variables with an aim of achieving scientific parsimony or economy of description (Harman, 1967). The particular factor analytic technique used in this study was the Principal Factor Analysis (PFA) rotated under the varimax criterion to achieve orthogonal structure. For an item to qualify for inclusion into a factor, it was a priori determined that such an item must load at least 0.400 on that factor. This rule is commonly used in past studies to determine items to be included in a particular factor (Boshier, 1971; Burgess, 1991).

\section{RESULTS}

\section{Respondent Characteristics}

Nearly three-quarters $(74.6 \%)$ of the respondents were in the age range $18-35$ years and 65 percent were female. Four-fifths $(80 \%)$ of the respondents were unskilled or semi-skilled with a qualification not higher than GCE or its equivalent with 56 percent enrolled more than once in non-credit programmes. A tenable explanation may be that most participants who desired a career choice but could not meet formal admission requirements found participation as a means to remedying their deficiencies, hence they were motivated to re-enroll in additional programmes. Others desiring to acquire new skills and competence in their jobs were also motivated to re-enroll after initial participation.

Sample information further revealed that after initial participation, there is a probability of 0.56 that an adult may participate in one additional programme, there is a probability of 0.28 that an adult may participate in at least two more programmes and there is a probability of 0.10 that an adult may participate in at least three more programmes. It was observed that 57.2 percent of the respondents had more than five years of job experience before enrollment and 51.6 percent were in government services, 26.1 percent in Business/Finance/Banking industry, 14.2 percent in Manufacturing/Production Construction industry. Additionally, sample information also revealed that 56.0 percent of the respondents were in the lower societal-class, 41.0 percent in the middle-class and only 3.0 percent in the upper-class. Possible conclusions may be that:

i) The desire for increased monetary returns, self esteem and self-actualisation were strong motivation for participation in non-credit programmes. Adults with many years of experience especially in the government services tend to discover that the only way up the ladder in their jobs was more skills and additional qualifications;

ii) The desire for professional advancement and escape from undesirable conditions in the workplace may be strong participation motivation for young adults with little or no skills. Being supervised by those who were initially juniors but returning from college with additional qualifications may be frustrating in a work environment and also a sufficient reason to motivate participation in further educational activities; 
iii) The desire to meet basic needs seem to exert a significant pressure on adult learners

of age range 18 - 35 years compelling about 28 percent of them after first enrollment to always be willing to re-enroll in at least two more programmes and 10 percent to reenroll in at least three more programmes.

It is note worthy to point out that only 20.9 percent of the respondents had the Associate of Arts degree, its equivalent or higher qualification out of which 7.5 percent had first degree or higher qualifications. Moreover, 3.0 percent of the later were in the upper societal class. With these statistics, it appears reasonable to think that participants were possibly motivated by the desires to satisfy some intrinsic socio-personal needs, to acquire new skills or advance professionally and to escape from frustrations arising from undesirable conditions in the work environment. From Table 2 the respondent's scoring (mean) of the factors of reasons motivating adult participation in noncredit programmes with the ranks is presented.. It is of interest to note that The Need to Define a Career Path ranked highest followed by The Need for Professional Advancement, then The Need for Self-Actualisation. The reason for this ranking is not far fetched. The majority of participants were of age $18-35$ years with little or no skills and qualifications not higher than GCE or its equivalent. The Table shows the hierarchy of needs motivating adult learners to participate in non-credit programmes. At the base of the hierarchy is the intrinsic socio-personal needs preceeding the need to escape undesirable conditions. This is not surprising because psychologists maintain that satisfaction of lower order needs are pre-requisites for satisfying higher order needs.

\section{Factor Content Analysis}

The rule for inclusion of an item into a factor was established a priori in the previous section. Based on this rule, our preliminary analysis findings identified all of the 35 items of REAP as adequate and appropriate for inclusion in at least one of the predetermined or newly validated factors prior to further analysis. An exploratory approach was adopted to verify the number of factors best accounting for the reasons of adult enrollment in non-credit programmes at CEES and also for the variation of the 134 responses to the thirty-five items of REAP. To achieve this end, the factor analytic solution was calculated for the following order: five, six, seven, eight, nine, ten, eleven, and twelve. The results were studied to determined the solution which best accounted for the total variation among the data. The adequacy of the solution was determined by identifying which order resulted in a more comparative, logically and statistically inter-pretable results.

The factor solution of order eight was identified as best for achieving scientific parsimony and economy of description, therefore, accounting for 68.2 percent of the total variation in the determinants of adult participation motivation in non-credit programmes at CEES. One of the eight predetermined factors was not confirmed but a new factor emerged in its place leaving the number of factors still at eight.

In the sequel, we discussed the factor contents of the Factor Analytic results. The 
factors, items (as numbered in REAP) comprising each factor and the partition of variance among the factors are set out in Table 2 .

Table 2: List of Items in Factors and Percentage of Variance

\begin{tabular}{|c|c|c|c|c|c|}
\hline & Rank & Item Number & MEAN & $\%$ of Var. & Cum $\%$ of Var. \\
\hline \multirow{2}{*}{1} & 7 & $3,4,1,2,8,5$ & & & \\
\hline & & $6,9,7,11$ & 2.15 & 15.1 & 15.1 \\
\hline 2 & 8 & $15,16,10,11,13,12,9,17$ & 1.77 & 10.9 & 26.0 \\
\hline 3 & & $20,14,19$ & 2.75 & 4.9 & 30.6 \\
\hline 4 & & $21,35,26,22,27,20$ & 2.97 & 10.5 & 41.4 \\
\hline 5 & & $24,25,27,1$ & 3.22 & 5.0 & 46.4 \\
\hline 6 & & $32,29,31,28,30,33$ & 2.29 & 12.2 & 58.6 \\
\hline 7 & 6 & $34,23,33$ & 2.15 & 5.1 & 63.7 \\
\hline 8 & 5 & $18,17,7$ & 2.22 & 4.5 & 68.2 \\
\hline
\end{tabular}

All the thirty-five items of REAP loaded sufficiently high to be included in at least one of the eight factors, therefore, all the items were considered to be major motivational reasons for adult participation in CEES non-credit programmes. The discussion of the factor contents now follows:

\section{Factor I: The Intrinsic Socio-Personal Needs}

Factor I is labelled Intrinsic Socio-Personal Needs and consists of ten items which identify respondents who enroll in CEES non-credit programmes to fulfill inborn sociopersonal needs in order to achieve a healthy social living and personal development. This factor accounts for over fifteen percent of the total variance. The items making up Factor I are presented below (as given in REAP). Reliability coefficients are given in parentheses. This pattern will be adopted in presenting subsequent factors:
Item \#. 3
4
$0.774(0.87)$
$0.752(0.80)$
$0.733(0.82)$
$0.730(0.76)$
Item \#. 5 6 9 7 11 Loading $0.699(0.88)$ $0.608(0.800$ $0.572(0.76)$ $0.483(0.80)$ $0.408(0.83)$

All the items initially listed as indicative of the Intrinsic Socio-Personal Needs clustered together with an extra item (11) to explain this factor. The extra item (11) was originally considered to be indicative of Factor II, "The need to escape undesirable conditions". However, item 11 loaded 0.408 on Factor I and 0.658 on Factor II therefore, it was included in both factors. It may be explained that since Factor I accounted for the largest portion of variance than any other factor, item 11 was also included in Factor I to broaden and sharpen its definition. A participant with the desire to fulfill intrinsic socio-personal goals could interpret item 11, "To overcome the frustration of day to day living" to mean "To improve my present frustrating social conditions and then achieve my social and personal goals". On the other hand, participants with the desire to escape undesirable conditions could interpret item 11 to mean "To overcome adverse 
conditions causing anxiety, tension and conflict in my daily living”. This group of adults may be motivated by the fact that participation could eventually provide an escape from adverse conditions and not motivated by the course content or course objectives.

Item 9 was initially listed under Factor III "The Need for self actualisation". Factor analytic results did not support the inclusion of item 9 in Factor III but rather validated it for inclusion in Factor I. Including item 9 in Factor I may imply that participants view "Gaining insight into personal needs, strengths and inadequacies" as indictive of personal development rather than self-actualisation.

On the whole, it appeared that Factor I is made up of two sub-clusters: the first consisting of seven items $(3,4,1,2,8,5$ and 6$)$ with higher loadings and the second of three items $(9,7$ and 11) with lower factor loadings. The first sub-cluster tend to characterise the participants with the desire to satisfy inborn social needs but the second sub-cluster characterises the participants with the desire to gratify inherent personal needs. These two sub-clusters did not emerge as separate factors but clustered together to characterise participants with the desire to gratify inherent socio-personal needs in order to achieve a healthy social living and personal development. This justifies the 82 percent enrolled in personal development courses and 18 percent in non-personal development courses. This merger also justifies why Factor I accounts for 15 percent of the total variation in the determinants of adult participation motivation for non-credit courses.

In conclusion, Factor 1, "Intrinsic Socio-Personal Needs" was validated as a well defined and distinct group of reasons motivating adults to participate in non-credit programmes and was to be two-fold - inherent social need and personal needs.

\section{Factor II: The Need to Escape from Undesirable Conditions}

This factor labelled "The Need to Escape from Undesirable Conditions" consists of eight items of REAP presented below: Undesirable conditions may be emotional, mental, intellectual or physical conditions.

$\begin{array}{lccccc}\text { Item \#. } & 15 & 16 & 10 & 11 & 13 \\ \text { Loading } & 0.800(0.83) & 0.779(0.84) & 0.661(1.00) & 0.658(0.83) & 0.573(0.83) \\ \text { Item \#. } & 12 & 9 & 17 & & \\ \text { 'Loading } & 0.557(1.00) & 0.418(0.76) & 0.415(0.74) & & \end{array}$

The eight items of Factor II are compatible in meaning and accounts for 10.9 percent of the total variation in the determinants of adult participation motivation in non-credit programmes. Excepting item 9 initially included in Factor III, other items were originally listed in Factor 11. Inclusion of item 9 was not supported by the analytic results but in both Factors I and II. This may be an indication that participants view "gaining insight into personal needs, strengths and inadequacies" to mean "gaining understanding on how to achieve personal goals" as well as "finding a way to escape from 
unpleasant conditions arising from an inner feeling of deprivations, inadequacy and/or adverse conditions". An alternative implication may be that the need to escape from undesirable conditions is a much lower order need than intrinsic socio- personal needs. Therefore, according to Maslow's Theory, satisfaction of the need to escape from undesirable conditions may be a pre-requisite for gratification of the socio-personal needs. The ranking of these needs in Table 2 supports this argument. Items 15, 16, 10, 11, 13 and 12 (in that order) clustering together with higher loadings on Factor II may indicate that frustration, boredom, stress and routine activities termed as "undesirable conditions" forced adult learners to seek escape through enrollment in non-credit courses in order to escape tension and achieve excitement, variety and friendliness. The motivation, therefore, may not be in acquisition of knowledge or skills from participation but to find escape from undesirable conditions. Practically oriented programmes may be more exciting and appealing to such adults than purely intellectually oriented programmes. Enrollment Statistics in the Fall of 1996, show that over 45 percent of total enrollment in New Providence were in Personal Development (practically oriented) courses while 16 percent were in Professional Development courses and 29 percent in Up-grading and regular COB courses (intellectually oriented).

Finally, items 9 and 17 clustering with lower loadings appear to characterise adult learners with an inner feeling of inadequacy who also sought escape through participation in non-credit courses. This inner feeling of inadequacy is another undesirable condition. Therefore, the two sub-clusters emerged as a distinct and separate factor of reasons why adults participate in non-credit programmes.

\section{Factor III: The Need for Self-Actualisation}

Factor III was defined as "The Need for Self-Actualisation" which is manifested by the desire to discover oneself and one's potential. Maslow's Theory ranks self-actualisation as the highest-in the hierarchy of human needs. Maslow compares failure to satisfy this need with vitamin or iodine deficiency conditions. Three items 14, 19 and 20 clustered within the factor which accounts for 4.9 percent of the total variance. Items loading sufficiently high on Factor III are given below:
Item \#.
20
14
19
Loading
$0.623(0.92)$
$0.614(0.81)$
0.542
$(0.85)$

Initially, three items 9,14 and 18 were listed under this factor, but the factor analytic results showed that items $9(0.061)$ and $18(0.099)$ may not be adequate in explaining this factor. Extra items (19 and 20) clustered with item 14 to explain the exact views of participants who enrolled in non-credit programmes in order to satisfy the need for selfactualisation. To a large extent, the items are compatible in meanings.

Initially item 20 was listed as indicative of professional advancement needs (Factor IV), but it was validated as capable of explaining the need for self-actualisation. It may mean that participants view self-discovery as an indicator of professional advancement. 
Also it may mean that satisfaction of the need for self-actualisation is a pre-requisite for satisfying the need for professional advancement. Therefore, the need for self- actualisation may be a much lower order need than the need for professional advancement. That is, when participants discover themselves and their potential they are able to make advances in their professions. As noted earlier, most of the participants had little or no skills and were general and junior labourers, therefore, they desire to discover their potential in order to make advances in their profession. This may explain why in the Fall of 1996, professional and personal development courses accounted for 61 percent of overall enrollment at CEES.

In conclusion, the need for self-actualisation has been validated as a distinct group of reasons for adult participation in non-credit courses. The need for professional advancement is shown to be a much higher order need than the need for self-actualisation among participants in non-credit courses. The ranking of the need in Table 2 using the mean scores of factors also confirms this assertion.

\section{Factor IV: The Need for Professional Advancement}

This factor defined as "The Need for Professional Advancement" is manifested by the desire to acquire new skills, competence, attain a higher status and face challenges. Participants appear to be desiring skills in order to improve competence and face challenges with little or no stress. Six items 21,35, 26, 22, 27 and 20 clustered together with this factor accounting for 10.5 percent of the total variation in adult participation motivation in non-credit programmes. Items included in this factor are given below:

Item \#. 21 $\begin{array}{ll}35 & 26 \\ 0.783(0.77) & 0.738(0.80)\end{array}$ Loading 0.794 (0.82) $0.618(0.81)$ $0.609(0.78)$ 0.51 20

Initial items listed under Factor IV were 20, 21, 22, and 24, but items 21, 35, 26, 22, 27 and 20 were validated as a group of reasons explaining the need for professional advancement. Item 23 was returned as inadequate for explaining the need for professional advancement. It loaded 0.343 on this factor. It appears that participants accorded item 23, "To keep up with competition" a lower priority because most of them belonged to general labour and were junior workers facing little or no competition. However, participants accorded item 21 "To acquire a higher professional status", a higher priority and also item 35, "To have increase in salary". Giving items $21,35,26$ and 22 higher priority over item 27 is not by chance. It appears to suggest that participants actually valued acquisition of skills and competence more than earning a higher educational qualification. "Increased monetary returns " was hypothesized as one of the needs motivating an adult to participate in non-credit programmes and item 35 was used in explaining it. This need was not validated as a separate need motivating adults participation in non-credit courses, but rather item 35 was included in Factor IV "The Need for Professional Advancement" It could be logically explained that participants may be of the opinion that professional advancement brings along with it increased monetary returns. Therefore, the need for increased monetary returns did not 
emerge as a separate and distinct group of reasons but as a need that may be satisfied whenever the need for professional advancement is satisfied. Giving item 20 the lowest priority in Factor IV may not be surprising because item 20 was accorded highest priority in Factor III, " The Need for Self-Actualisation", therefore, item 20 was validated as being capable of explaining two groups of reasons why adults participate in non-credit programmes.

\section{Factor V: The Need to Define a Career Path}

The need to define a career path was predetermined as a factor of reasons why adult learners participate in non-credit courses because more than 70 percent of the respondents were under the age of 35 and had little or no skills on the job. This need usually carries with it a sense of incompetence, deprivation and inadequacy. Initially listed as capable of defining this need were items 24, 25, 26 and 27, but items 19, 24, 25 , and 27 were validated as adequate in defining this need. Five percent of the total variance was accounted for by this factor. The list of items included in Factor $V$ is given below:
Item \#. 24 25 27 19 Loading $0.705(0.78)$ $0.590(0.76)$ $0.457(0.78)$ $0.436(0.85)$

Factor analytic results showed that item 26, "To meet formal requirements", was not adequate for defining the need for a choice of career path. Instead it was included in Factor IV, "The Need for Professional Advancement". It appears that participants interpreted item 26 to mean "meeting formal professional standards" as opposed to "meeting formal requirements for a desired career".

Item 27 was accorded a lower priority also in this factor than items 24 and 25 . This is also suggestive of the fact that participants desired a career not a higher educational qualification, justifying the 82 percent enrollment in Personal Development courses out of 693 total enrollment in non-credit courses. It is not surprising that item 19 was given lowest priority in Factor $\mathrm{V}$ because it was included in both Factors III and V. This probably indicates that Factor $\mathrm{V}$ is of a higher order need than Factor III. The ranking in Table 2 using Factor mean scores by respondents confirms this conclusion.

\section{Factor VI: The Need to Serve The Community}

This need stems from an individual's felt obligation to serve the community either in the political, social and/or religious arena. Participation in further educational activities prepares the adult learner to fulfill his desire to serve the community. Five items $28,29,30,31$ and 32 were originally determined to be defining the need to serve the community, but the items $28,29,30,31,32$ and 33 given below were shown to be adequate by the factor analytic results:
Item \#.
32
29
31
28
30
33
Loading $0.856(0.83)$
$0.836(0.82)$
$0.793(0.83)$
$0.722(0.84)$
$0.721(0.79)$
$0.49(0.80)$ 
Item 33 was included in both Factors VI and VII although it was originally listed under Factor VII. Its inclusion in Factor VI may be justified by the fact that Factor VI accounts for a larger portion of variance more than many other factors, therefore, it was included to broaden its meaning. Another explanation may be that the need to serve the community is associated with the need to fulfill external expectations. The ranking in Table 2 shows that the need to fulfill external expectations is a lower order need than the need to serve the community. Therefore, expectations from the community appears to be a strong motivation for the desire to serve the community. These expectations may come from some influential community activities or political and religious mentors who may be grooming these participants for some responsible positions in the society or church. This group of reasons explains a significant portion of the total variance and are highly compatible in meaning, therefore, defining another distinct factor of reasons why adults enroll in non-credit programmes.

\section{Factor VII: The Need to Fulfill External Expectations}

Based on previous research the need to fulfill external expectations was hypothesized as a separate factor of reasons for adults participation in non-credit programmes. This factor is very close in meaning to Boshier's (1982) "Desire to comply with formal requirements" factor and similar to Miller's (1992)"External Expectations" factor. This need may arise from the desire to meet formal requirements set out by employers, professional or social associations or may arise from the desire to fulfill expectations of some one who has significant influence on the life of the adult. The adult learner feels the obligation to participate in non-credit programmes, not necessarily for what the programme has to offer but because of external pressure.

Initially, items 33 and 34 were listed under this factor, but the factor analytic results validated an extra item (23) which adds to explain the need to fulfill external expectations. The items and their loadings for this factor are given below:
Item \#.
34
23
33
Loading
$0.726(0.78)$
$0.668(0.85)$
$0.560(0.80)$

This factor accounts for 5.1 percent of the total variance. Item 23 was included in Factor VII but not in Factor IV as previously listed probably because "to keep up with competition" was regarded as an external expectation by the respondents. However, the inclusion of this item helps in defining distinctly the exact views of participants who enroll in non-credit programmes in order to fulfill external expectations.

\section{Factor VIII: The Need for Self-Esteem}

Esteem needs are among the basic human needs. This need represents the desire to develop a positive self-concept, mastery and competence, Adults with a strong desire to fulfill this need may use participation in educational activities as a stepping stone to achieving this need. This factor was not originally identified as a group of reasons 
motivating adult learners to enroll in non-credit programmes. The factor defined was "The Need for Increased Monetary Returns", originally identified as the eight group of reasons, but this did not emerge as a distinct factor; rather a new factor "the need for self-esteem" emerged in its place with three items given below:
Item \#.
18
17
7
Loading
$0.739(0.78)$
$0.457(0.74)$
$0.415(0.80)$

Factor VIII, "The Need for Self-Esteem" emerged as a distinct and separate group of reasons for adult participation in non-credit programmes accounting for 4.5 percent of the total variance.

The emergence of this factor may indicate that participants with low self-esteem enrolled in non-credit programmes as a means of improving their minds and intellect in order to develop a positive self concept, mastery and professional competence. The item loadings above appear to suggest that this factor of reasons for adult participation motivation is made up of two sub-clusters. The primary sub-cluster with higher factor loading (0.739) consists of item 18 only. This sub-cluster tends to suggest that the feeling of low self-esteem was as a result of the participants' positions on the job. The sample information reveals that 80 percent of the respondents had little or no skills with a qualification not higher than GCE or it equivalent. The secondary sub-cluster has lower factor loadings (0.457 and 0.415) and consists of items 17 and 7 respectively. This sub-cluster tends to suggest that the feeling of low self-esteem was a result of the participants' social status. Sample statistics reveal that 97 percent of the respondents belonged to the lower and middle classes of the society, having qualifications below a first degree or it equivalent.

The inclusion of item 17 in both Factors II and VIII may imply that undesirable conditions were the primary causes of low self-esteem. Also, the use of item 7 to define Factors 1 and VIII appears to suggest that low self-esteem was resultant of participants inability to to fulfill their inherent socio-personal goals. This tends to imply that in the hierarchy of needs of the participants, the need for high self-esteem is a higher order need than the intrinsic socio-personal needs. This is confirmed by the ranking in Table 2 .

\section{SUMMARY AND CONCLUSION}

This research attempts to use statistical tools to understand characteristics of participants in CEES non-credit programmes and to intrepret adult participation in non-credit programmes in the light of traditional motivational framework. The data indicated that about eighty percent of the respondents had little or no skills and possessed qualifications not higher than GCE equivalent. Personal and professional development needs in adddition to the need for self-actualisation were major motivation for participation in non-credit programmes at CEES. Data analysis revealed also that 74.6 percent of the respondents were young adults in the age range of 18 - 35 years and 51.6 percent were participants from government services (ministries and parasatals). Moreover, about 92.5 percent of the respondents belong to the lower and middle classes of the society 
with a qualification lower than a first degree or its equivalent and 82 percent of participation in non-credit courses were in the personal and professional development needs. These appear to suggest where the market for CEES courses is. Most respondents participated more than once in CEES non-credit programmes. Sample information revealed that after first participation in a non-credit programme, the probability that an adult in New Providence would participate again in:

(I) One additional programme is 0.56

(ii) at least two additional programmes is 0.28

(iii) at least three additional programmes is 0.10

The desire for a career choice was found to be a stronger motivation for adult participation in non-credit courses than achievement of a higher educational qualification. Additional skill-aquisition and improved job performance were accorded a higher priority by respondents than higher educational qualification. Increased monetary returns was not found to be a major motivation for adult participation in non-credit programmes.

The factor analytic results validated all the thirty-five items of REAP as major reasons why adults participate in non-credit programmes in New Providence. These items clustered into eight distinct groups which exhibited a high degree of compatibility among the items. These factors accounted for 68.2 percent of the total variation in adult participation motivation in non-credit programmes. The ranking of these factors reveals the hierarchy of needs in adult participation motivation in non-credit programmes as follows: Factors 5, 4, 3, 6, 8, 7, 1 and 2 (in that order). Growth motivated needs are higher order needs than deficiency motivated needs. Maslow's Theory maintains that gratification of lower order needs is a pre-requisite for satisfaction of higher order needs. Participants satisfy deficiency oriented needs in order to satisfy growth oriented needs. Career and professional development needs are at the peak of the hierarchy of needs of participants in non-credit programmes.

\section{CONTRIBUTION OF RESEARCH FINDINGS TO THE THEORY OF LEARNING}

A model of Equilibrium State of an adult learner was developed earlier in the study as a three-stage process - Equilibrium, Dis-equilibrium and Learning. This model sheds more light into what happens in the learning process of an adult. We finally develop a model which explains adult participation motivation in an educational activity as the summary of the major findings and conclusions of this study. (Model is given below).

Initially, the adult learner identifies a need or a group of needs which may be welldefined or undefined. Well-defined needs consist of needs clearly identified and precisely defined by an adult learner in a way that could be measured with a considerable degree of accuracy. Well-defined needs are in two categories: Growth-oriented needs and deficiency-oriented needs. Growth-oriented needs are those arising from the desire to satisfy professional and social goals. Such needs include: The Need to Choose a Career, The Need for Professional Advancement, Intrinsic Scoio-Personal Needs, The 
Need for Self-Actualisation, The Need to Serve The Community and The Need to Fulfill External Expectations. Deficiency-oriented needs arise from the desire to remedy particular deficiencies or meet certain requirements which include the need to escape from undesirable conditions and The need for self esteem. We maintain that there may be some overlappings, between these categories.

On the other hand all other needs which cannot be stated in this manner may be referred to as "undefined needs". An adult learner may know that these needs exist and has the desire to satisfy these needs but cannot state or define them clearly in a measurable manner. An adult having well-defined needs sets out measurable goals which are indicators of these needs and are used to measure the extent to which these needs are satisfied. It is necessary to note that the more goals are measurable the more needs were well-defined. An adult learner motivated by needs initiates an action or a behaviour as a means of achieving his goals. However, an adult learner with undefined needs also initiates a behviour to achieve some undefined goals. This action involves the decision to participate in an educational activity. On completion of this activity, the adult learner achieves his goals thereby satisfying his needs. Hence, a level of equilibrium higher than the one before participation in the Learning Process (satisfaction) is attained.

Fig 2: The Model of Adult Participation Motivation in an Educational Activity.

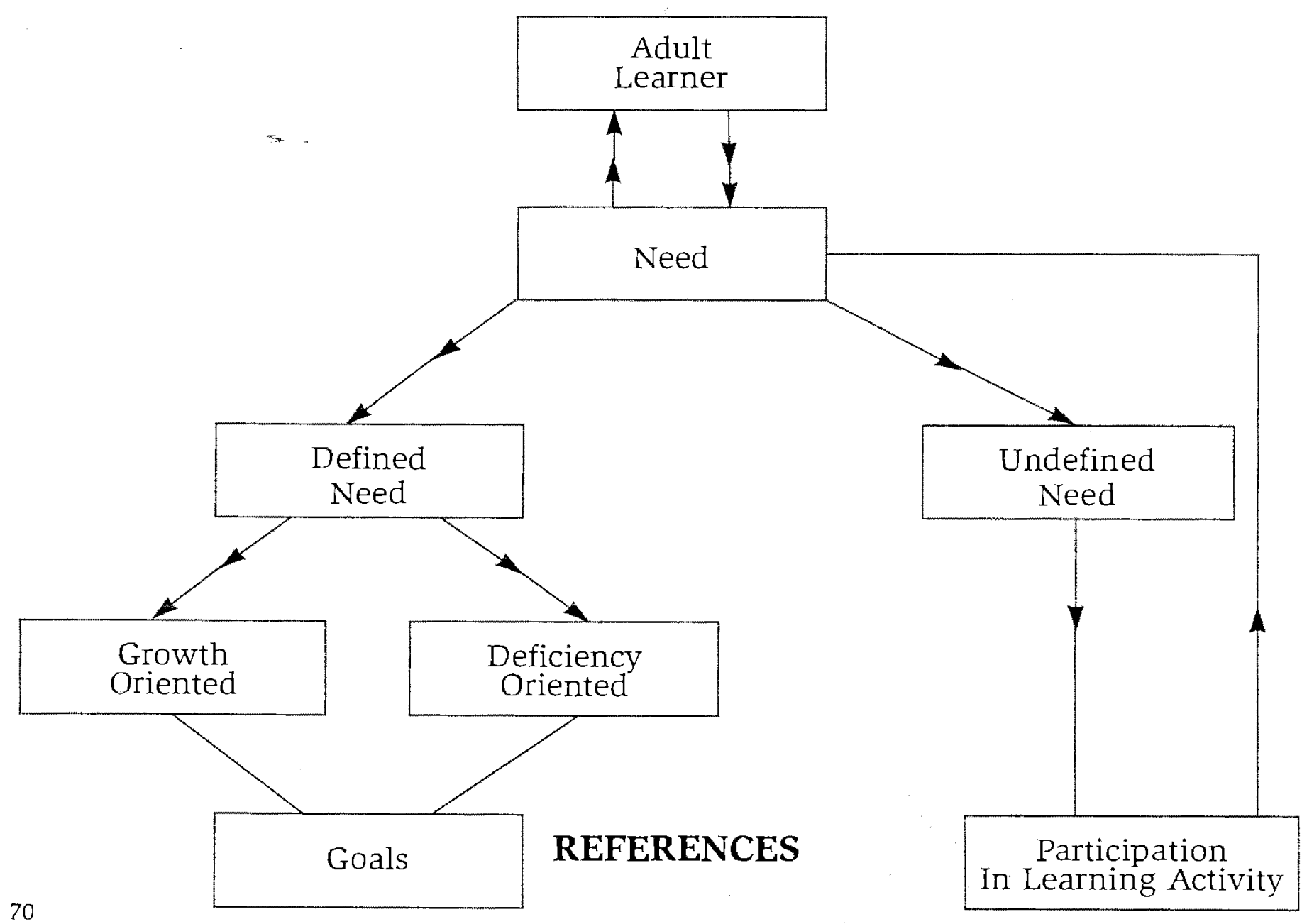


Birkenfiolz, R., Harbstreit, S., and Law, D.(1990). Research Priorities for adult education in agriculture in The North Central Region. Joumal of Agricultural Education $31(4)$.

Boshier, R. (1971). Motivation orientations of Adult Education Participation: A factor analytic exploration of Houle's Typology. Adult Education 21 (2), 3-26.

Boshier, R. (1982). Education Participation Scale. Vancouver: Learning Press.

Burgess, P. (1971). Reasons for Adult Education Participation in Group Educational Activities. Adult Education 22 (1), 3-29.

Christmas, O. (1990). Instructional factors associated with the level of participation in adult agricultural education programmes. Proceedings of Central Region 44th. Annual Research Conference in Agricultural Education.

Cronbach, L.J., Glejser, G., Nanda, N., and Rajaratnam, N. (1972). The Dependability of Behavioral Measurements: Theory of Generalizability for Scores and Profiles, NY, Wiley.

Douglah, M. Some Perspectives on the Phenomenon of Participation. Adult Education, 20 (Winter), 88-98.

Harman, H. H., (1967). Modern Factor Analysis: University of Chicago Press, 4. Houle,C.O (1961). The Inquiring Mind. University of Wisconsin Press: Madison.

Maslow, A. H. (1954). Motivation and Personality (New York: Harper).

Maslow, A. H. (1961, 1968). Towards a Psychology of Being. First and Second Edition (NY: Van Nostrand).

Miller, B. E. (1992). Participation Motivation in Off-Campus Agricultural Credit Programmes: Journal of Agricultural Education, (Summer 1992).

Moore, P.G. (1990). The Skills Challenges of The Nineties. JRBS, Series A, Vol 153 (3).

Nicholson, D. H. (1995). Why Adults Attend School: An Analysis of Motivating

Factors. University of Missouri Bulletin, September.

Nunnally, J. C. (1976). Psychometric Theory. New York: McGraw Hill.

OECD, (1996). Background Note on OECD Meeting of Education Ministers, Paris, 1617 January 1996: SG/COM/New (96). 3, Paris P3. 
Sheffield, S. B. (1964). The Orientations of Adult Continuing Learners In Daniel Solomon; ed. The Continuing Learner: Chicago: Centre for the Study of Liberal Education for Adults, 1-22.

Wagner, E. D. (1994). In Support of a Functional Definition of Interaction. American Journal of Distance Education, 8 (2) 6.

World Bank (1996). World Bank Employment Services and Promotion Project, Terms of Reference 2. ILR 134 (6), 1995/96.

\section{AUTHOR}

Nsima D. Udoko is a lecturer in the Department of Mathematics at The College of The Bahamas. Formerly, he was employed as a Lecturer at the University of Uyo, Nigeria and as a Senior Lecturer at The College of Agriculture, Jamaica.

Dr. Udoko's studies in Mathematics and Statistics were undertaken at the University of Benin and University of Ibadan, Nigeria. He received a Doctor of Philosophy Degree in Statistics from the University of Ibadan, Nigeria and a Certificate in Computer Applications from Delaware Valley College, Pennsylvania, United States. He is a Fellow of the Royal Statistical Society, London. His research intexplate Econometric Analysis, Forecasting, Modelling and Applied Statistics. 